\title{
Analyzing the analytics: data privacy concerns
}

\author{
Maria Petrescu $^{1}$ Anjala S. Krishen ${ }^{2}$
}

Published online: 4 May 2018

(C) Macmillan Publishers Ltd., part of Springer Nature 2018

The Facebook and Cambridge Analytica incident is just one example in a string of events in recent years that underlines the difficulties of managing information and data privacy in the digital environment. In this context, even executives from the digital world, such as Apple and IBM, have called for more oversight on personal data use (Reuters 2018). While many question the preparedness of businesses and policymakers regarding online consumer privacy issues, we all still acknowledge that we must now focus on productive research on this topic. As such, studies regarding the intersection between data privacy and marketing analytics are particularly important. As researchers show, it is essential to analyze digital data privacy to build trust through sound business practices in data analytics and to improve marketing activities (Leonard 2014; Martin and Murphy 2017). In addition to building trust, research shows that proper and transparent privacy policies lead to higher consumer fairness perceptions and distributive justice (Krishen et al. 2017).

The United States Bill of Rights includes privacy protections into different Amendments, including the First, Third, Fourth, and Fifth (Martin and Murphy 2017). Throughout decades, research has presented broad and diverse definitions of information and data privacy (Adams 2017). Information privacy has been defined as "the right to select what personal information about me is known to what people" (Westin 1968). Privacy is also considered the

Maria Petrescu

mpetresc@nova.edu

1 H. Wayne Huizenga College of Business and Entrepreneurship, Nova Southeastern University, 3301 College Ave., Fort Lauderdale, FL 33314, USA

2 University of Nevada, Las Vegas, USA control of the distribution and use of consumer personal, demographic, and online activity information (Foxman and Kilcoyne 1993). From the consumer perspective, concern for information privacy identifies data collection, unauthorized use, improper access, and error (misrepresentation) as the four key dimensions of concerns; these fall into the two broad categories of risk beliefs and protection beliefs (Raschke et al. 2014).

\section{Data privacy online}

Studies indicate that some of the debated topics related to digital information privacy include various national privacy laws and regulations, the social benefits of using big data, and culturally acceptable practices (Leonard 2014). For example, while research reveals that countries with tighter privacy regulations experience fewer privacy problems, greater control can have a downside and lead to lower advertising effectiveness and other consumer marketing outcomes (Martin and Murphy 2017). Studies also conclude that in conditions of higher perceived control over privacy, consumers are nearly twice as likely to click on personalized ads (Tucker 2014). Regarding privacy notices, research finds that consumers are increasingly frustrated with them, and reading notes come from concern for privacy, positive perceptions about their comprehension, and higher levels of trust in the text (Milne and Culnan 2004; Milne et al. 2006).

Research emphasizes the fact that big data can create several privacy threats, including for persons whose data are only indirectly involved or whose information has not even been collected (Matzner 2014; Raschke et al. 2014; Sánchez and Viejo 2017). Peltier et al. (2009) present a framework for understanding consumer information 
privacy issues in direct and interactive marketing based on three broad dimensions: (1) multiple publics, (2) information channel developments, and (3) the publics' responses to privacy actions.

In this context, marketing analytics research should analyze topics such as consumers' attitudes towards the use of different levels of privacy controls and regulations, knowledge regarding privacy tools, and differences among digital platforms. In addition, social media marketing research can emphasize the risks and tradeoffs regarding consumer privacy with particular interest in the role of data analytics. Consumer-to-consumer communication channels, microblogs, blogs, social networking applications, and other means by which they reveal their location, beliefs, and any other private information are all important avenues for future research (Scheinbaum et al. 2017). Consumer attitudes and use of notices, and the midpoint in the balance between privacy and the use of analytics to offer better, more personalized services are also of interest. The different publics and various information channels, as well as the differences among them, are also topics to consider.

\section{Data privacy in the Internet of Things}

The Internet of Things (IoTs) includes new applications that allow consumers to check the status of their home appliances from their smartphones, monitor their homes, and synchronize their devices, which leads to a higher risk of having private information collected and shared (Adams 2017). Weinberg et al. (2015) argue that the IoTs can solve problems and create opportunities for different publics, including consumers, businesses, communities, and policymakers, but also issues and costs related to privacy.

With regard to the IoT, privacy is related to smart things and services surrounding consumers. It assumes individual control over the collection, processing, and storage of personal information, as well as awareness and control over the use and dissemination of this information (Walker 2016; Weinberg et al. 2015; Ziegeldorf et al. 2014). In this context, researchers note that regulations are not in correlation with the advances in the market, due to information overload, unclear information use, and the speed with which data are exchanged (Adams 2017; Walker 2016). Because of this, consumers are even less likely to know that their information has been breached or shared. At the same time, in the world of marketing analytics, marketers need as much information as possible to be collected through the IoT so as to offer consumers an efficient and personalized experience. It is in this area that marketing analytics research can have a deeper focus, into topics such as (1) privacy regulations related to IoT and how they impact the use of consumer data, (2) new marketing metrics and their relationship to consumer privacy, and (3) consumer perceptions and attitudes towards IoT data collection and processing.

\section{Data privacy in research}

While debates related to data privacy in the digital world usually stem from data sharing issues, studies find that in 2017 only about half of the research data were shared and a much smaller proportion openly, helping discoverability and reuse (Stuart et al. 2018). A Springer Nature study shows that, in their attempts to archive, publish, and share data, researchers face time constraints and a lack of knowledge around data standards, metadata and curation expertise, repository options, and funder requirements (Stuart et al. 2018). Regarding the specifics of big data and marketing analytics, it would be especially interesting to find the potential that a different data mining perspective or the use of a separate method could have in the analysis of a dataset and the discovery of new information if it became available to others. However, the issues confronting data breaches and privacy in practice could be affecting researchers' attitudes towards sharing data and putting more effort into knowing data standards and curation issues. Not surprisingly, more research is needed even in terms of this marketing research topic and how it intersects with data analytics and research efficacy and quality.

Overall, we propose that a more structured approach and a stream of research is needed with regard to data privacy and its relationship to marketing analytics, as these topics have profound implications for consumers and marketers. Both consumer and marketer attitudes towards privacy and behavioral outcomes as well as the common regulatory policies that all parties are willing to reach to benefit everyone are topics that could be of particular help for digital and IoT users, managers, researchers, and policymakers.

\section{References}

Adams, M. 2017. Big data and individual privacy in the age of the Internet of Things. Technology Innovation Management Review 7 (4): 2-24.

Foxman, E.R., and P. Kilcoyne. 1993. Marketing practice, and consumer privacy: Ethical issues. Journal of Public Policy and Marketing 12: 106-119.

Krishen, Anjala S., Robyn L. Raschke, Angeline G. Close, and Pushkin Kachroo. 2017. A power-responsibility equilibrium framework for fairness: Understanding consumers' implicit privacy concerns for location-based services. Journal of Business Research 73: 20-29. 
Leonard, P. 2014. Customer data analytics: Privacy settings for 'Big Data' business. International Data Privacy Law 4 (1): 53-69.

Martin, K.D., and P.E. Murphy. 2017. The role of data privacy in marketing. Journal of the Academy of Marketing Science 45: 135-155.

Matzner, T. 2014. Why privacy is not enough privacy in the context of "ubiquitous computing" and "big data". Journal of Information, Communication and Ethics in Society 12 (2): 93-106.

Milne, G.R., and M.J. Culnan. 2004. Strategies for reducing online privacy risks: Why consumers read (or don't read) online privacy notices. Journal of Interactive Marketing 18 (3): 15-29.

Milne, G.R., M.J. Culnan, and H. Greene. 2006. A longitudinal assessment of online privacy notice readability. Journal of Public Policy and Marketing 25 (2): 238-249.

Peltier, J.W., G.R. Milne, and J.E. Phelps. 2009. Information privacy research: Framework for integrating multiple publics, information channels, and responses. Journal of Interactive Marketing 23 (2): 191-205.

Raschke, R., A.S. Krishen, and P. Kachroo. 2014. Understanding the components of information privacy threats for location-based services. Journal of Information Systems 28: 227-242.

Reuters. 2018. Apple, IBM chiefs call for more data oversight after Facebook breach. https://www.reuters.com/article/us-chinaforum-data/apple-ibm-chiefs-call-for-more-data-oversight-afterfacebook-breach-idUSKBN1H20JU.

Sánchez, D., and A. Viejo. 2017. Personalized privacy in open data sharing scenarios. Online Information Review 41 (3): 298-310.

Scheinbaum, A.C., A.S. Krishen, A. Kachen, A. Mabry-Flynn, and N. Ridgway. 2017. Mommy blogs and online communities: Emotions and cognitions of working mothers. In The dark side of social media: A consumer psychology perspective, 1st ed, ed. A.C. Scheinbaum, 225-241. New York: Routledge.

Stuart, D., G. Baynes, I. Hrynaszkiewicz, K. Allin, D. Penny, M. Lucraft, and M. Astell. 2018. Practical challenges for researchers in data sharing. White paper. Springer Nature. https://doi. org/10.6084/m9.figshare.5975011.
Tucker, C.E. 2014. Social networks, personalized advertising, and privacy controls. Journal of Marketing Research 51: 546-562.

Walker, K.L. 2016. Surrendering information through the looking glass: Transparency, trust, and protection. Journal of Public Policy and Marketing 35 (1): 144-158.

Weinberg, B.D., G.R. Milne, Y.G. Andonova, and F.M. Hajjat. 2015. Internet of Things: Convenience vs. privacy and secrecy. Business Horizons 58: 615-624.

Westin, A.F. 1968. Privacy and freedom. Washington and Lee Law Review 25 (1): 166-170.

Ziegeldorf, J.H., O.G. Morchon, and K. Wehrle. 2014. Privacy in the Internet of Things: Threats and challenges. Security and Communication Networks 7 (12): 2728-2742.

Dr. Maria Petrescu is an associate professor of marketing at Nova Southeastern University. Her research interests are digital marketing, international marketing, and entrepreneurship. She participated and published in prestigious conferences and publications, such as the Journal of Marketing Management, Journal of Retailing and Consumer Services, Journal of Product and Brand Management and the International Review of Entrepreneurship, as well as a book on Viral marketing and social networks.

Dr. Anjala S. Krishen is an associate professor of marketing and international business at the Lee Business School at University of Nevada, Las Vegas. Her interdisciplinary research interests include areas within decision making in rich environments, including heuristics and choice set design, e-marketing and social networking, and database marketing. She has been published in top business journals, including Journal of Business Research, European Journal of Marketing, Journal of Advertising Research, Psychology \& Marketing, Information \& Management, International Journal of Advertising, and Journal of Marketing Education. 